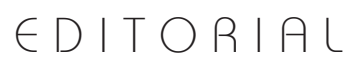

Motrivivência Ano XXIV, No 38, P. 07-11 Jun./2012

http://dx.doi.org/10.5007/2175-8042.2012v24n38p7

\title{
UM NOVO TEMPO, APESAR DOS PERIGOS...
}

\author{
No novo tempo, apesar dos castigos \\ Estamos crescidos, estamos atentos, estamos mais vivos \\ Pra nos socorrer, pra nos socorrer, pra nos socorrer \\ No novo tempo, apesar dos perigos \\ Da força mais bruta, da noite que assusta, estamos na luta \\ Pra sobreviver, pra sobreviver, pra sobreviver \\ Pra que nossa esperança seja mais que a vingança \\ Seja sempre um caminho que se deixa de herança \\ No novo tempo, apesar dos castigos \\ De toda fadiga, de toda injustiça, estamos na briga \\ Pra nos socorrer, pra nos socorrer, pra nos socorrer \\ No novo tempo, apesar dos perigos \\ De todos os pecados, de todos enganos, estamos marcados \\ Pra sobreviver, pra sobreviver, pra sobreviver \\ No novo tempo, apesar dos castigos \\ Estamos em cena, estamos nas ruas, quebrando as algemas \\ Pra nos socorrer, pra nos socorrer, pra nos socorrer \\ No novo tempo, apesar dos perigos \\ A gente se encontra cantando na praça, fazendo pirraça
}

(Música “Novo Tempo” de Ivan Lins)

Esta edição inaugura um novo tempo no itinerário deste projeto de editoração. É um novo tempo que está imerso numa enorme crise estrutural do capital. Esta crise, conforme anunciamos na edição passada, vem provocando a destruição dos direitos dos trabalhadores em todo o mundo e no Brasil, proletarizando a classe trabalhadora, precarizando-a, conforme se pode perceber nas intensas batalhas travadas entre capital e trabalho, que se traduzem numa plêiade de greves na educação e outros setores da vida brasileira. Essa crise continua sendo transmitida pela mídia brasileira e internacional, mostrando a todos nós a obsolescência do sistema capitalista.

Em meio a esse novo tempo, fomos impelidos a realizar mudanças necessárias, visando a agilizar o processo de construção e veiculação do conhecimento. Essas 
mudanças são de forma e não de conteúdo. O novo formato não trará prejuízos para o conteúdo crítico da revista, tanto nos textos, quanto no editorial; aliás, uma marca da Motrivivência. Vale destacar que igualmente essas mudanças não obedecem necessariamente a uma imposição dos critérios avaliativos do sistema Qualis-Capes, mas sim a uma autocrítica e à vontade de tornar este veículo cada vez mais acessível aos leitores, tanto da academia (estudantes e professores imersos na formação inicial e na pós-graduação), quanto aos professores que atuam nas redes públicas de ensino.

Com efeito, mudamos a forma, mas não o conteúdo. A mudança da forma não irá alterar o rigor da avaliação dos textos e, primordialmente, o conteúdo ético e estético da revista. Essa relação dialética pode ser percebida na estética crítica da poesia como método e na veiculação das linguagens e imagens (fotografias), cujo conteúdo traduz a nossa tentativa de realizar a relação entre ciência e arte. Esse esforço pode ser visto também na tentativa de veiculação de textos e editoriais críticos, publicados desde sempre. Tudo isso é importante salientar, quando falamos em mudanças, lembrando que a Motrivivência tem, à medida do possível, tentado garantir no seu projeto editorial um compromisso político-pedagógico, que se traduz na problematização de temas e questões que sejam de relevância pública, que sejam articuladas a um processo de educação crítica, que tem o papel de buscar o modo como as relações de poder e desigualdade (social, cultural e econômica), em sua miríade de combinações de formas e complexidades, manifestam-se e são postas em questão na educação formal e não-formal (APPLE et al., 2011)'.

Neste sentido, aproveitamos o ensejo para enfatizar que um projeto editorial deve considerar as imensas desigualdades sociais e diversidades socioculturais em que vivemos; não pode deixar de ter um papel fundamental para as consciências em prol de um processo de transformações sociais, culturais, econômicas e outras. Neste sentido, a relevância de um periódico não escapa à reflexão crítica sobre o papel dos intelectuais nas diversas instâncias acadêmicas. Assim, os editores devem nortear-se pelos princípios ético-políticos e ideológicos de uma efetiva educação crítica dos leitores. Isso significa dizer que os editores não podem fazer parte de uma intelligentsia despreocupada, como alguém que vive na sacada. Em outras palavras, "nossos esforços intelectuais são cruciais, mas eles não podem ficar observando tudo ao lado, de maneira neutra e indiferente, das lutas nas quais o futuro da humanidade está em jogo" (BOURDIEU, citado por APPLE et al., 2011) ${ }^{2}$. Nestes termos, o papel do editor como intelectual pode ser sintetizado nas palavras de Milton Santos: "ser intelectual é exercer diariamente rebeldia contra conceitos assentados, tornado respeitáveis, mas falsos. É, também, aceitar o papel de criador e propagador do desassossego e o papel de produtor do escândalo necessário" (SANTOS, 2007, p. 147) ${ }^{3}$.

Retomando a nova forma da revista, como havíamos disponibilizado na nossa página e na edição anterior, a revista não

\footnotetext{
APPLE, Michel W. et al. Educação crítica: análise internacional. Porto Alegre: Artmed, 2011.

Bourdieu, citado por Apple et al. (2011)

SANTOS, Milton. O intelectual e a universidade estagada. In: LEITE, Maria Angela P. Encontros Milton Santos. Rio de Janeiro: Beco do Azougue, 2007.
} 
terá mais o mesmo número de sessões e, tampouco, será exclusivamente temática. De fato, em lugar da temática para toda a revista, vamos restringir o tema eleito a um dossiê, dando agilidade desta forma à publicação da revista e garantindo, a exemplo de muitos periódicos, um espaço mais aberto e amplo para a tematização de problemas e temas polêmicos da área. Contudo, urge reconhecer, por outro lado, que o velho formato marcou profundamente a história da revista, à medida que, a duras penas, conseguimos garantir, em edições temáticas passadas, verdadeiras antologias recorrentes e marcantes, como por exemplo: formação profissional, megaeventos, mídia, educação física na educação infantil, mundo do trabalho e outros temas pungentes.

Ainda quanto às mudanças no formato e política de seções, registramos com muita alegria a acolhida que tivemos pela comunidade acadêmica, pois o número de artigos tanto para a seção Temática quanto para as de Artigos Originais e Porta Aberta aumentou consideravelmente, observando um fluxo de submissões bastante acima da média com que essa editoria vinha trabalhando. Por conta disso, ao tempo que agradecemos aos autores, pedimos sua compreensão com possíveis demoras no processo de avaliação dos originais, uma vez que, da mesma forma, estamos reformando e ampliando nosso corpo de revisores, contando com a colaboração voluntária de muitos pesquisadores da área, a quem também aproveitamos para agradecer.

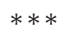

Nesta edição, a sessão dossiê tem como escopo abordar os Programas Sociais de Esporte e Lazer na Escola e na Comunidade, cuja ementa foi: reflexões críticas e propositivas sobre a forma e o conteúdo dos programas sociais de esporte e lazer que vem sendo desenvolvidos na escola e na comunidade por instituições governamentais e não-governamentais (terceiro setor). A ideia era trazer para o debate os programas e projetos que vivificam as políticas públicas de esporte e lazer, marca dos governos Lula e Dilma Roulssef na área (mas não só destes), sob a mácula da inclusão social.

Pela importância do tema, consideramos que o debate apenas foi iniciado no dossiê; com algumas exceções, muitos textos recebidos se configuravam como relatos "por dentro" dos programas, de pessoais envolvidas diretamente com sua execução e/ou gestão, sem o devido distanciamento a esses programas. Nesse sentido, os textos contemplam mais uma avaliação interna e críticas aos programas em si, em seus aspectos administrativos e aspectos de implementação, do que propriamente uma problematização e radicalização dos limites das políticas chamadas de inclusivas. Há, também, em contrapartida, críticas consistentes à falsa questão entre inclusão e exclusão social e sobre a necessidade da comunidade acadêmica da educação física, problematizar esses programas e projetos, com menos entusiasmo e pragmatismo e outras categorias de análise.

De todos os modos, ficamos contentes em abrir esse debate necessário, considerando as lacunas existentes na produção do conhecimento na Educação Física, principalmente, quanto às dimensões epistemológicas, ontológicas e ideológicas da chamada inclusão social, pela via da cultura corporal e de movimento.

Pelo exposto, fica aqui a nossa provocação aos leitores, no sentido de intensificar 
as críticas aos limites e possibilidades das políticas públicas, de onde se originam os programas e projetos publicados no dossiê. Neste sentido, indicamos a leitura do livro "Cidadania Negada: políticas públicas e formas de viver dos trabalhos", organizado por Patto (2009) ${ }^{4}$. No livro, a autora, ao se referir às políticas públicas na atualidade, as considera como "políticas públicas precárias, voltadas para os direitos sociais", que produzem efeitos "cosméticos" que só pioram o quadro geral (p. 13). A autora afirma que é neste contexto que as ações, projetos e programas supostamente promovem a "inclusão", disfarçando a "exclusão". O que aparece como exclusão não passa de "inclusão marginal". Assim, projetos públicos ou privados alardeiam o "resgate da cidadania" e, como regra "assistencialista", enfraquecem os "beneficiários" ao transformá-los em receptores agradecidos de favores vindos dos "de cima". Tudo isso vem acompanhado dos procedimentos astutos de manipulação de estatísticas que mentem sobre o número de beneficiários de políticas públicas, abrindo espaço à culpabilização dos que não contribuem para a mágica dos números.

Nesta mesma linha de raciocínio, Silva et al. (2007, p. 34-136) fazem uma longa reflexão sobre o conceito de exclusão, argumentando suas posições com base em Robert Castel (1997) ${ }^{6}$. Este autor afirma que tal conceito é estanque e limitado, pois já designa "estados de privação". Segundo ele, no lugar da exclusão, há zonas de inclusão social, algo bem oscilante nos dias de hoje; a zona de transição é a da vulnerabilidade social. Castel sugere então o conceito de "desfiliação", o que diz respeito aos "cidadãos" em zona de isolamento, sem defesas sociais e a destruição dos seus direitos pelo próprio Estado. Para ele, "desfiliação" seria uma ruptura em relação às redes de integração primária, referindo-se, portanto, a uma das zonas de trânsito possíveis na sociedade capitalista que está situada entre o "trabalhar" e suas proteções decorrentes, e a total desconexão com o viver "em" e o viver "com" segurança.

O conceito de desfiliação permite refazer o percurso da ruptura com a segurança em cada âmbito social, até chegar à exclusão. Nesta linha de reflexão, desfiliado pode indicar desconexão com espaços de oportunidades, atividades e direitos que a sociedade oferece a seus cidadãos em termos de trabalho e segurança social, saúde, educação, salário digno, alimentação, moradia, transporte e, é claro, o esporte. A desfiliação levaria, portanto, à inexistência social, cuja oscilação da zona de vulnerabilidade e instabilidade não é, necessariamente, vivenciada apenas pelos mais pobres e sim por todas as classes. Nesses meandros, as zonas de vulnerabilidade são áreas intermediárias que ficam em intervalos, nas quais estão em suspenso a inclusão e a desfiliação (FERREIRA, 2002 p. 128-129) ${ }^{7}$.

Por fim, para Martins $(1997)^{8}$, "não existe exclusão: existe contradição, existem

4 PATTO, Maria Helena S. (org.). A cidadania negada: políticas públicas e formas de viver. São Paulo: Casa do Psicólogo, 2009.

5 SILVA, Maurício Roberto et al. Políticas públicas para o esporte: cidadania e inclusão social. In: SILVA, Mauricio Roberto (org.). Esporte, educação, estado e sociedade. Chapecó: Argos, 2007.

6 CASTEL, Robert et al. Desigualdade e a questão social. São Paulo: EDUC, 1997.

7 FERREIRA, Raquel C. O jovem e o trabalho: desfiliação e criatividade. Devir, Belo Horizonte, v. 1, n. 2, 2002.

8 MARTINS, José de Souza. Exclusão social e a nova desigualdade. São Paulo: Paulus, 1997. 
vítimas de processos sociais políticos e econômicos excludentes". Deste modo, não há exclusão, cujo rótulo termina por, contraditoriamente, empurrar os "empobrecidos" pelo próprio sistema para fora de seus direitos e das relações sociais, privando-os dos direitos que dão sentido a essas relações. Por outro lado, pode-se dizer que esse movimento empurra os sujeitos para "dentro" (inclusão), para a condição subalterna de reprodutores do sistema econômico, como se esses não fossem capazes de resistências à subalternidade ao sistema e críticas aos processos de exclusão includente. A ideia de "exclusão" é pobre e linear, pois, quando as políticas públicas sociais atuais (esportivas e outras) justificam a necessidade de incluir os excluídos, deixa de discutir as formas pobres, insuficientes e precárias de inclusão social e a necessidade de transformação social.

Encerramos provisoriamente o debate sobre os programas e projetos oriundos das políticas públicas para a Educação Física, o esporte e o lazer, esperando que nos próximos números possamos continuar o debate em textos e resenhas sobre essa problemática. Deixamos para reflexão o verso de Paulo Paes: para quem sempre pediu tão pouco, o nada é positivamente o exagero...

No que se refere aos artigos originais de demanda contínua, esta edição traz para o debate textos que problematizam as questões geracionais (envelhecimento) e práticas corporais; o trato com o conhecimento na Educação Física Escolar; os referenciais curriculares; o corpo olímpico; a Copa de 2014 no Pantanal; a capoeira nas escolas; as diretrizes curriculares nacionais para a Educação Física e suas falsas interpretações.

Como última remanescente da antiga estrutura, a Porta permanece Aberta, pois, a partir de agora todas as outras antigas seções (Cientifique-se, Ponto de vista, Grupos de
Estudo e Experimentando) tem sua morada neste espaço. Assim, a revista continua aberta, com temas diversificados (ensaios, pesquisas exploratórias, relatos de experiências, resenhas, etc.) e não menos importantes do que os artigos e o dossiê. Esta seção continua o seu curso, se constituindo num espaço permanente, tanto para iniciantes na pesquisa, quanto para os pesquisadores experientes. Essa expressão pode ser constada nas diversas temáticas de suma relevância social e acadêmica que se seguem neste número: educação física e saúde coletiva; metodologia do ensino e da pesquisa em sociologia do esporte; corpos, identidade e mídia; o lazer e o mundo do trabalho.

Antes de encerrarmos, vale uma referência ao nosso homenageado especial dessa edição. Por toda a sua vasta contribuição aos estudos do lazer, nas dimensões teórica, da formação e da gestão, o nome do professor Nelson Carvalho Marcellino já seria naturalmente lembrado. Numa edição cuja seção temática está relacionada justamente às políticas públicas de esporte e lazer, área na qual sua presença tem sido ímpar em todo o país, nada mais pertinente do que homenagea-lo.

Por fim, como despedida, sugerimos nos encontrar no próximo número:

no novo tempo, apesar dos perigos a gente se encontra cantando na praça, fazendo pirraça...

Florianópolis, agosto de 2012.

Maurício Roberto da Silva; Giovani De Lorenzi Pires (editores) 